\title{
PIEZOSURGERY VERSUS CONVENTIONAL ROTARY INSTRUMENT FOR INFERIOR ALVEOLAR NERVE LATERALIZATION PRIOR TO IMPLANT PLACEMENT: (COMPARATIVE CLINICAL STUDY)
}

\author{
Ingy Mohamed Chehata* and Ghada Mohamed Abdelmonim**
}

\begin{abstract}
Aim of the study: Evaluation of the inferior alveolar nerve (IAN) neurosensory function, postoperative pain and edema following the placement of an implant with inferior alveolar nerve lateralization using piezo-surgery versus conventional rotary instruments.

Materials and methods: Twenty four partially edentulous patients were selected for this study. Twelve patients underwent inferior alveolar nerve lateralization for Implants placement using Piezosurgery device (Group A), while the other twelve patients underwent inferior alveolar nerve lateralization for implant placement using conventional rotary surgical bur (Group B). Operation duration, postoperative pain, edema, and patient satisfaction were primary assessed and compared between the two groups at 2,5 and 7 days postoperatively, also inferior alveolar nerve affection as a secondary outcome was assessed subjectively and objectively and compared between the two groups throughout the follow up intervals occurred at 2, 8 \& 24 weeks postoperatively.
\end{abstract}

Results: There was a statistical significant difference in all of the primary and secondary assessments between the two groups in favor of group A at all of the follow up intervals, except at the operation duration assessment where piezosurgey (Group A) had statistically significant higher operation duration than group B.

Conclusion: The inferior alveolar nerve lateralization (IANL) technique using conventional surgical burs has a higher initial rate of sensory dysfunction, postoperative pain and edema than with using Piezosurgery. The somatosensory evoked potential method is considered more informative, reliable and diagnostic parameter than other subjective and conventional clinical methods.

KEY WORDS: Posterior mandibular atrophy, dental implant, Inferior alveolar nerve lateralization, Piezosurgery, Trigeminal somatosensory evoked potential (TSEP).

* Assistant Professor of Oral and Maxillofacial Surgery. Faculty of Dentistry. October University of Modern Sciences and Art. Egypt

** Lecturer of Oral and Maxillofacial Surgery.Faculty of Dentistry Cairo University 


\section{INTRODUCTION}

The surgical challenge of patient rehabilitation with edentulous posterior mandibles continues due to the limitation imposed by the presence of the inferior alveolar nerve (IAN). Several techniques have been described for treating severe posterior mandibular atrophy and subsequent rehabilitation with implant supported prostheses ${ }^{[1]}$. Some authors favor the use of short implants that avoid interfering with the IAN and so avoid the resulting sensory disturbance ${ }^{[2]}$ Other authors prefer carrying out vertical guided bone regeneration, proceeding to implant placement right after graft maturation [3]. Inferior alveolar nerve (IAN) repositioning, although it is surgically more demanding, but it offers a viable alternative allowing the use of longer implants and makes it possible to increase implant primary stability ${ }^{[4]}$.

In 1977 Alling reported the first case of IAN repositioning (lateralization) ${ }^{[5]}$; thereafter in $\mathbf{1 9 8 7}$ Jenson and Nock modified the technique [6], whereby the mental foramen was included at the performed osteotomy, taking the inferior alveolar nerve to a new position which requires transacting the incisor branch of the alveolar nerve, while lateralization technique allows mobilization of IAN laterally without nerve transaction for subsequent implant placement Although both techniques are associated with complications mentioned in the literatures, IAN transposition technique shows higher risks of complications than lateralization technique ${ }^{[7-10]}$. (Fig.1).

Although inferior alveolar nerve lateralization has many advantages but the main advantage is that it allows placement of longer implants, improving the crown-root proportion and the biomechanics. But, it also carries some disadvantages, such as neurosensory disturbance involve Paraesthesia, Anesthesia, dysesthesia, disturbed or loss lower lip and chin sensation due to primary surgical trauma as a result of stretching or vascular damage

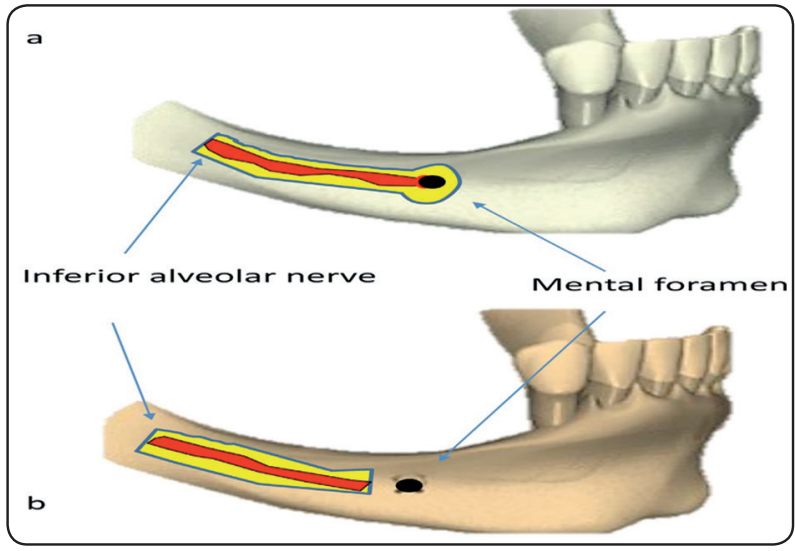

Fig. (1) Scheme of the two reposition techniques: a. Transposition, the mental foramen included at the osteotomy; b. Lateralization ${ }^{[1]}$

or secondary complications from edema or hematoma. ${ }^{[11-14]}$ Vasco et al. ${ }^{[15]}$ using finite element analysis, assessed bone loss risk comparing $15 \mathrm{~mm}$ with 7 $\mathrm{mm}$ implants, concluding that there was greater risk of bone loss with the use of short implants.

In the literature, several methods for cutting the cortical bone during IAN lateralization procedure were introduced including the use of conventional surgical carbide fissure burs, discs and recently Piezosurgery devices. Conventional Rotating instruments have been used for ma $\mathrm{y}$ years However, bone overheating and damage to adjacent tissues are the main drawbacks related to the use of these methods ${ }^{[4]}$. Piezosurgery had been increasingly applied in several techniques at the field of maxillofacial surgery as it has accurate and selective cutting, preventing thermal damage, preserving of soft-tissue structures with the policy of reducing risk of neurosronsory affection during exposure with appropriate irrigation and reduced bleeding which enable better visibility of the inferior alveolar nerve (IAN) and cutting area. ${ }^{[16-19]}$.

Therefore, this current study was designed to assess neurosensory deficits, postoperative pain and edema following implant placement by inferior alveolar nerve lateralization (IANL) using 
Piezosurgery device versus conventional rotary surgical burs.

\section{PATIENTS \& METHODS}

\section{Study design}

A randomized control trial conducted on Twenty four patients with edentulous posterior mandible. The patients were divided equally and randomly into two groups. Placement of implants in patients of both groups was performed simultaneously in an atrophied posterior mandible by IAN lateralization either using a Piezosurgery device (Group A) or using conventional rotary surgical bur. (Group B).

\section{Inclusion criteria}

All patients were selected according to the following criteria:

- Atrophied posterior mandible provided with residual alveolar bone height of $\leq 8 \mathrm{~mm}$ above the inferior alveolar canal.

- No history for previous grafting procedures or implant placement in the site planned for nerve lateralization.

- None of the patients had systemic conditions which could affect bone metabolism or predicted outcomes or precluding minor oral surgical procedures.
- No history of neurological illness were recruited

Clinical examinations were conducted to demonstrate that all patients fulfilled the selected inclusion criteria. Cone beam computer tomography (CBCT) were performed Pre-operatively to all patients for the assessment of the position of the mandibular canal in relation to the upper and lower border of the mandible, bone length and thickness, and planning for implant position, depth and angulation, for both groups and Post-operatively to assess implants positions and angulations.

\section{Operative procedure}

\section{Group A}

Under local anesthesia, mucosal incision superior to the mental foramen extending approximately $1 \mathrm{~cm}$ beyond the anticipated osteotomy site was performed. This followed by reflection of the mucoperiosteal flap to expose the mandibular body and the mental nerve. Blunt dissection was then performed in order to identify and isolate the mental nerve.

Osteotomy using a Piezosurgery device was performed. (Fig. 2) The anterior end of the osteotomy extended $2-3 \mathrm{~cm}$ posterior to the mental foramen to avoid any loop of the nerve while the posterior osteotomy end was located $1-2 \mathrm{~cm}$ beyond the intended position of the most distal implant for passive positioning of IAN

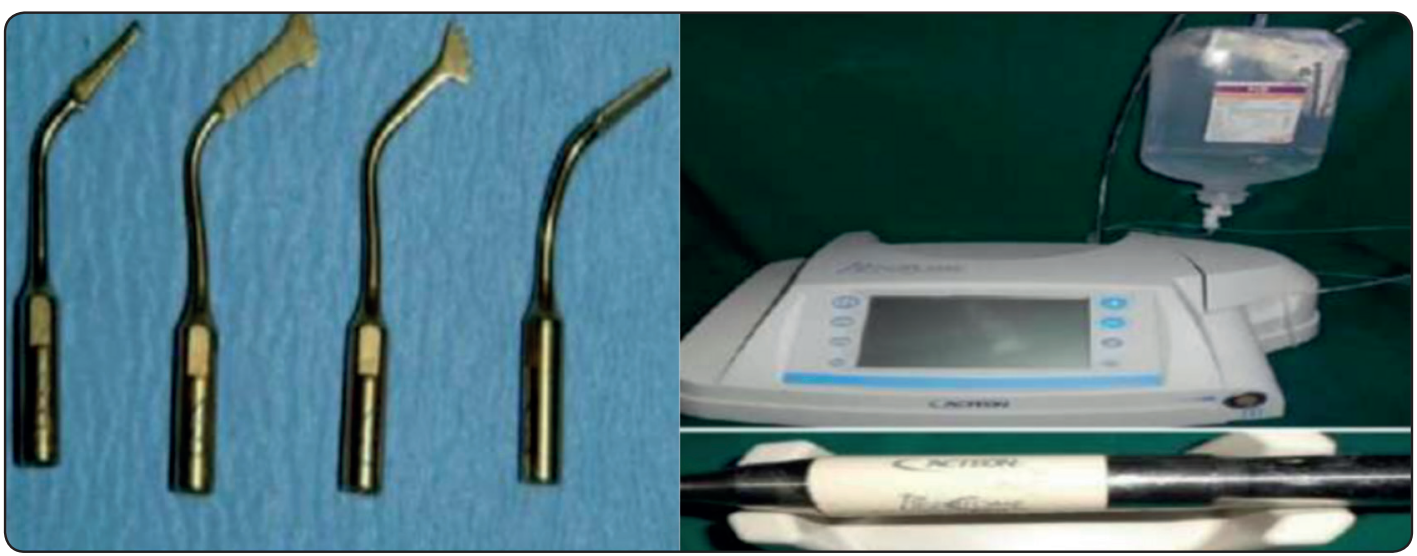

Fig. (2): Piezosurgery device 
Following careful removal of the posterior rectangular segment of the cortical bone overlying the nerve and identification of the neurovascular bundle retracted laterally, cylindrical endosseous implants with Platelet Rich Fibrin (PRF) were placed medially to the inferior alveolar nerve using standard techniques. Bone block was repositioned to cover the osteotomy. The flap was then sutured by interrupted silk sutures.(Fig.3)

\section{Group B:}

Same surgical procedure performed for group A, except using conventional rotary surgical burs with copious irrigation for the mandibular osteotomies needed for nerve lateralization. (Fig 4)

\section{Post -operative care}

Early Postoperative instructions and medications were prescribed for all patients. Including extraoral
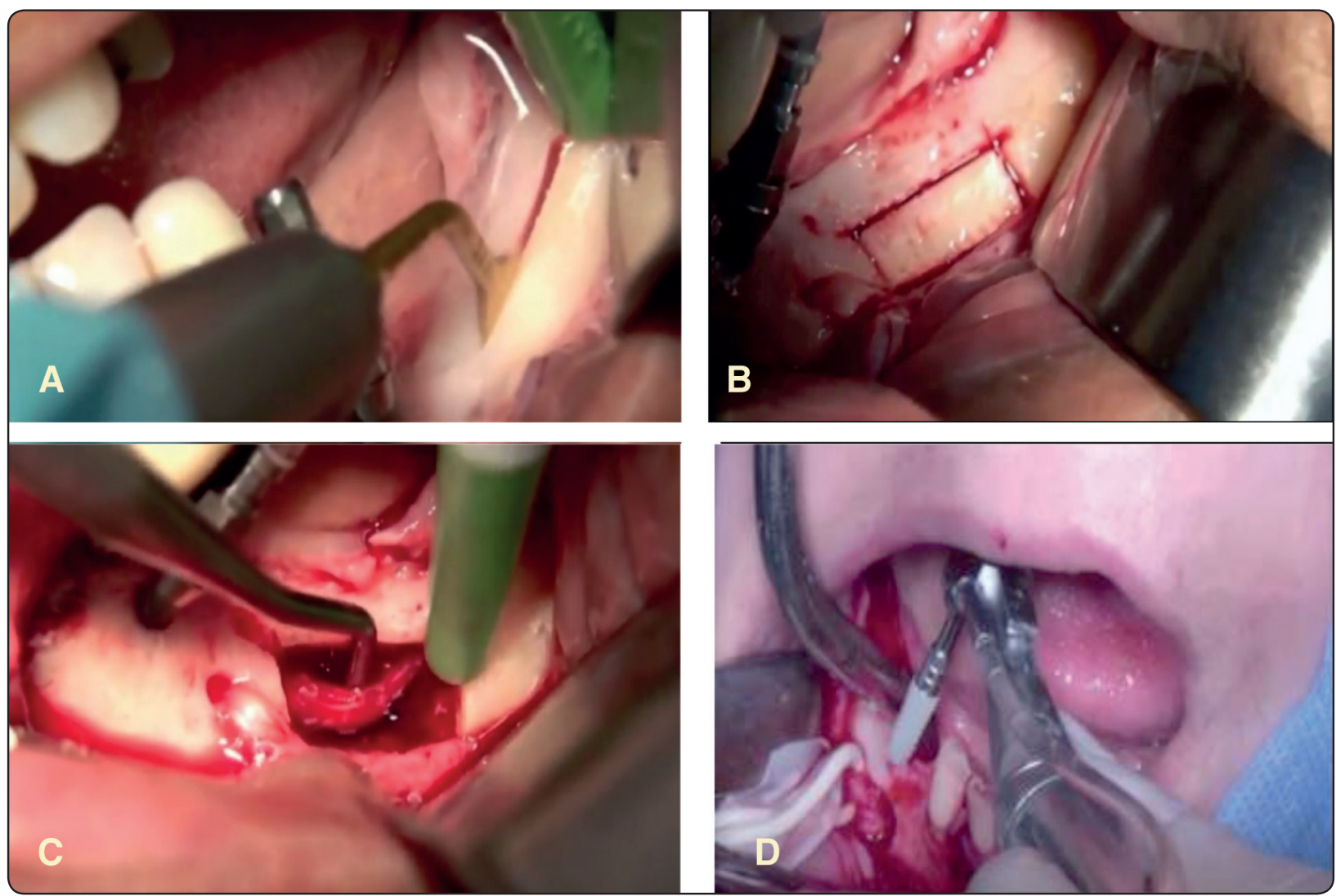

Fig. (3): (A) Alveolar bone cutting using Piezosurgery device (B) After complete cutting of lateral window by Piezosurgery (C) Identification of the neurovascular bundle laterally (D) Implants insertion after IANL.

ice packs placement, Chlorhexidine Gluconate Oral Rinse $0.12 \%$ mouthwash 3 times daily for the first week starting from the next day after surgery, Amoxicillin $500 \mathrm{mg} 3$ times a day for 3 days, Ibuprofen $400 \mathrm{mg}$ three times daily for pain relief and swelling control whenever required.

The operative duration was recorded from the beginning of incision until the end of the suture technique. Postoperative pain was assessed using visual analog scale (VAS) from scale zero to ten, while postoperative edema was evaluated by The degree ranked from $0-3$ (0: no edema; 1 : mild edema (just visible); 2: moderate edema (local); 3: severe edema (extended)) all these parameters were performed at 2,5 and 7 days after surgery. However, Long term follow -up for neurosensory assessment of the IAN function was performed for

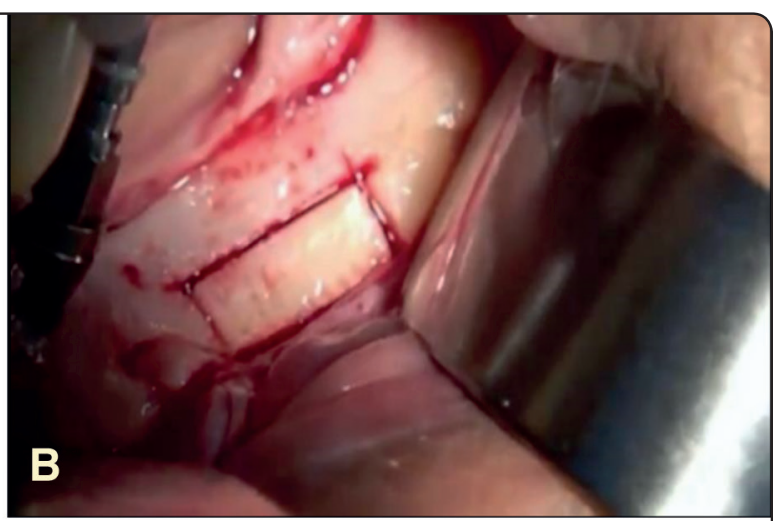




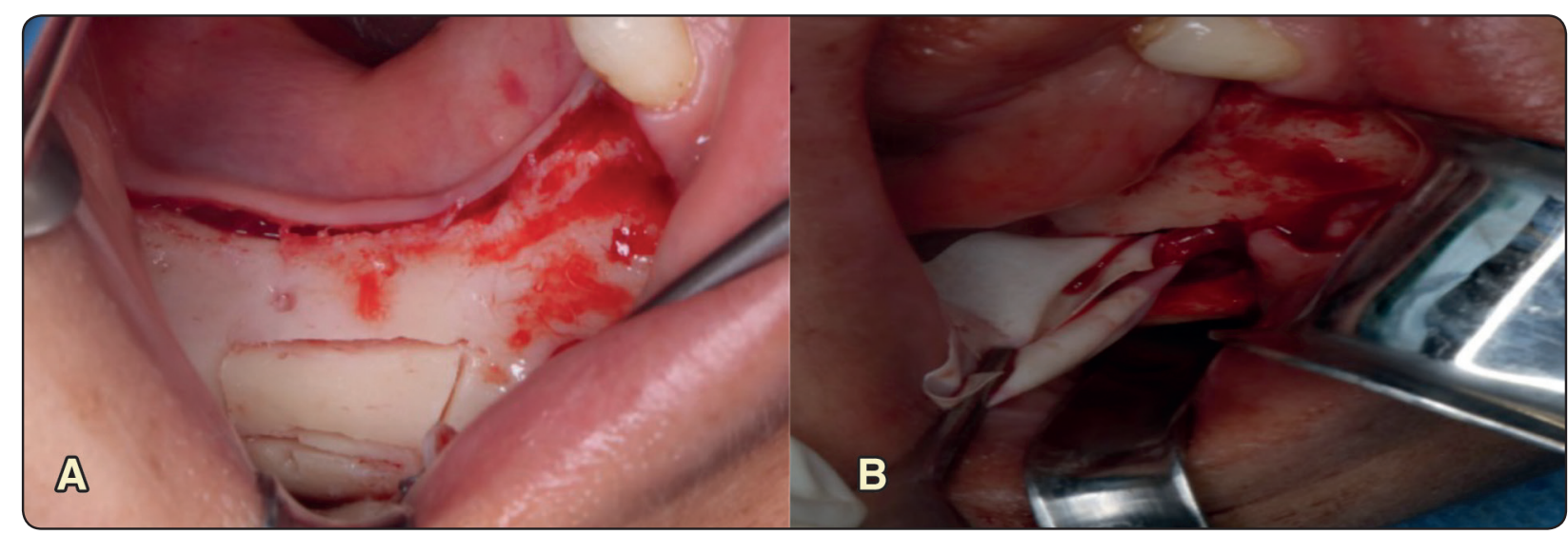

Fig. (4): (A) Complete cutting of lateral window by conventional rotary instrument (B) Identification of the neurovascular bundle laterally.

all Patients at 2, 8 \& 24 weeks postoperatively in both groups through the following tests:

\section{a) Subjective tests}

1) Patient questionnaire: Using patients own impression of the neurosensory function of their lower lip and chin. A score was given from 1 to 5 based on visual analogue scale. (5) Fully normal sensitivity, (4) almost normal sensitivity, (3) reduced sensitivity, (2) almost numb and (1) completely numb.

2) Two- Points Discrimination test: A caliper was opened progressively in 2-mm increments until the patient could discriminate the caliper ends as 2 separate points of contact. The following scores were used: $\mathbf{0}=$ normal sensitivity (patients could discriminate between the 2 tips at a distance shorter than $14 \mathrm{~mm}$ ), $\mathbf{1}=$ decreased sensitivity (patients could distinguish between tips only when the calipers were open between 14 and $20 \mathrm{~mm}$ ), $\mathbf{2}=$ No sensitivity (patients could not distinguish between the tips even if they were more than $20 \mathrm{~mm}$ apart ).

3) Light Touch test was performed using small piece of cotton wool with the patient's eyes closed; a stimulus was randomly applied to the test sites during 1 of 2 intervals separated 10 seconds apart. Each facial zone of the lower lip and the mental skin was lightly touched in order to check the touch perceptibility. A positive or negative reply was the only option at each point.

4) Brush Directional Discrimination test : The brush monofilament was stroked across the skin in $1 \mathrm{~cm}^{2}$ area, positive response is recorded if the sensation and perception of brush direction are

5) Postoperative pain (VAS): Using visual analogue scale from zero to ten, (zero=no pain, ten=the most severe pain), post-operative pain to patients from both groups was assessed at 2,5 and 7 days postoperatively.

6) Postoperative edema: was assessed using a scale from zero to three. $(0=$ no edema, $1=$ mild edema, $2=$ moderate edema, $3=$ severe edema) for both groups at 2,5 and 7 days postoperatively.

7) Operative duration: was measured starting incision until the end of the suture technique.

\section{b) - Objective test}

Trigeminal somatosensory evoked potential (TSEP) was achieved using Schnauzer-Myos unit. Monopolar surface recording electrodes were fixed to patients scalps. The recording electrodes were 
placed contra-lateral to the sides of stimulation $2 \mathrm{~cm}$ posterior to $\mathrm{C} 3$ and $\mathrm{C} 4$ at the coronal suture (according to international 10-20 system recording sites).Reference electrodes were placed at patients mid frontal sites and the arrays were earthed by ground electrodes placed behind patients ears, while stimulating electrodes were applied on skin side of the lip opposite to the premolars. The electrical stimulator provided stimuli at a rate of $2 /$ second, each stimulus lasted for $0.1 \mathrm{sec}$. The stimulus intensity was adjusted by gradual increase up to the level, where minimal lip twitch could be observed. TSEP was repeated at least two times to confirm the reproducibility and reliability of the response. Latencies, amplitude for each TSEP were determined and tabulated. (Fig.5)

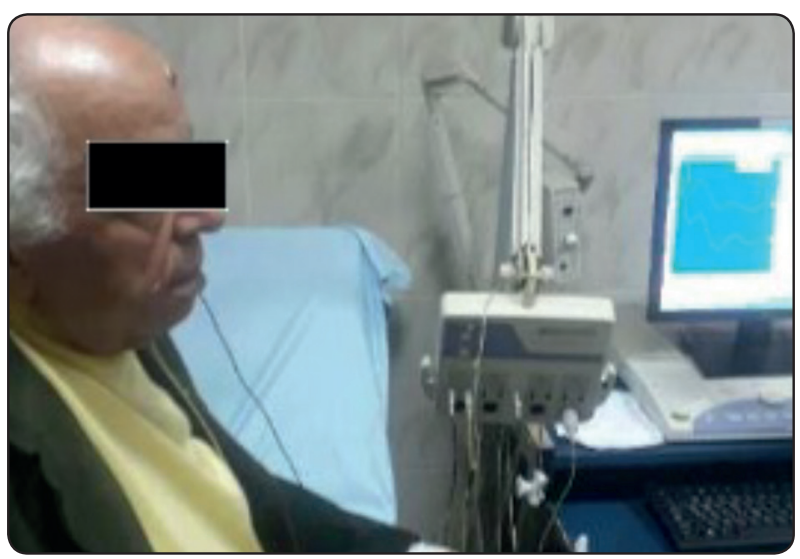

Fig. (5): TSEP test to a patient.

\section{Statistical analysis}

The collected data were statistically analyzed. The significance of difference between the preoperative and postoperative data regarding different neurosensory evaluation tests at the same group were assessed using the Student T test (paired). The two groups were compared to each other using also the Student T test (unpaired). The statistical analysis was carried out using SPSS ver. 22 software (statistical package for social science on windows 2013). A probability value $\mathrm{p} \leq 0.05$.

\section{RESULTS}

Twenty four patients were included in this study, twelve patients in each group. Patients' age range was $56.66 \pm 3.452$ years and $53.46 \pm 4.94$ years in group A and B respectively. All cases proceeded uneventfully with complete healing at the surgical site and resolution of all expected postoperative inflammation.

\section{Subjective Neurosensory tests}

\section{i) Patient questionnaire:}

Comparing means of observation periods revealed that there was statistically significant difference between the 2 groups at 2 weeks and 8 weeks $(\mathrm{p}<0.0001)$, while at 24 weeks, the difference was not statically significant $(\mathrm{p}=0.09)$. (Table.1)

Table (1) Comparison of mean, standard deviation values of the patients 'own Assessment questionnaire scores in both groups

\begin{tabular}{|c|c|c|c|c|c|}
\hline Group & \multicolumn{2}{|c|}{ Group A } & \multicolumn{2}{c|}{ Group B } & P value \\
\hline Period & Mean & Std Dev & Mean & Std Dev & \\
\hline $2 \mathrm{~W}$ & 3.62 & 0.96 & 1.54 & 0.78 & $<0.00001^{*}$ \\
\hline $8 \mathrm{~W}$ & 4.38 & 0.77 & 2.46 & 0.97 & $<0.00001^{*}$ \\
\hline $24 \mathrm{~W}$ & 4.85 & 0.38 & 4.54 & 0.52 & $0.09 \mathrm{~ns}$ \\
\hline
\end{tabular}

Significance level $p \leq 0.05$, *significant, $n s=$ non-significant

$N C=$ Not computed (same mean and std dev.)

\section{ii) Two-Points Discrimination test :}

Pre-operatively, there was no significant difference between both groups.

Comparison of subsequent observation periods revealed that Group A had statistically significant better results than Group B at 2 weeks, 8 weeks and 24 weeks.

$$
(\mathrm{p}=0.00, \mathrm{p}=0.0002, \mathrm{p}=0.0012 \text { respectively }),
$$




\section{iii) Light Touch (LT) test:}

Comparing the two groups regarding subjective assessment (LT) results revealed that:

Group A: $38.5 \%$ of cases recorded "no" At 8 weeks, $8 \%$ of cases recorded "no". At 24 weeks, $0 \%$ of cases in recorded "no".

Group B : At 2 weeks, $100 \%$ of cases of recorded "no", At 8 weeks, $38.5 \%$ of cases of recorded "no", At 24 weeks, $23 \%$ of cases recorded "no"

Student $\mathrm{T}$ test revealed that there was statistically significant $(\mathrm{p}=0.0006)$ between two groups at 2 weeks post operatively. While there was no statistical significance between the two groups at 8 $\& 24$ weeks post operatively $(\mathrm{p}=0.062),(\mathrm{p}=0.066)$ respectively.

\section{iv) Brush Directional Discrimination (BDD)}

Pre-operatively, both groups recorded the same value.

At 2 weeks, 100\% of cases of group B recorded "no", while $38.5 \%$ of cases in group A recorded "no". Student T test revealed that the difference between the two groups was statistically significant $(\mathrm{p}=0.0006)$,

At 8 weeks, $38.5 \%$ of cases of group B recorded "no", while $8 \%$ of cases in group

A recorded "no". Student T test revealed that the difference between groups was not statistically significant ( $\mathrm{p}=0.062)$, At 24 weeks, 23\% of cases of

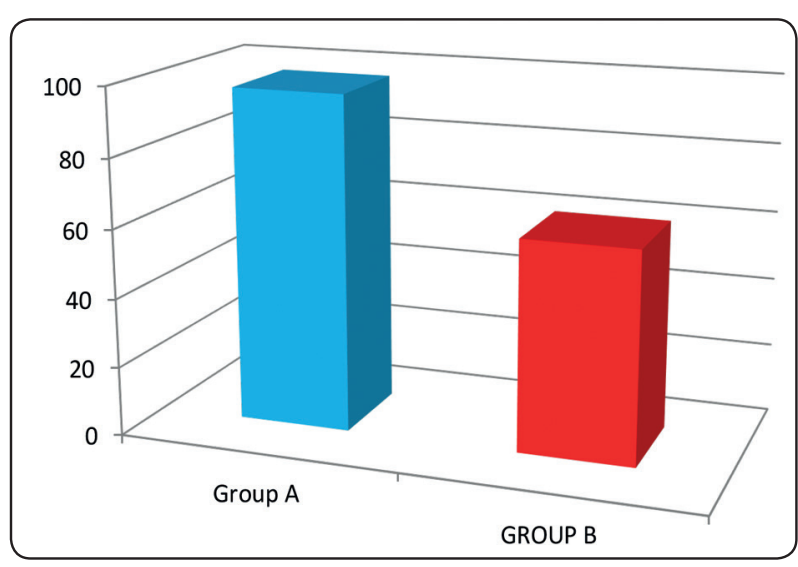

Fig. (6): Bar chart showing the operation duration of the two groups.

group B recorded "no", while $0 \%$ of cases in group A recorded "no". test revealed that the difference between groups was not statistically significant $(\mathrm{p}=0.066)$,

\section{v) Operative duration}

Comparing the operative duration of the two groups, there was a statistical significant difference between them. Group A had higher operative duration level than that of group B. (Fig.6)

\section{vi) Postoperative edema:}

There was a statistical significant difference $(\mathrm{P} \leq$ $0.05)$. between the two groups at all of the follow up intervals (2, 5 and 7 days post-operatively) in which group A had lower postoperative edema results than that of group B. (Fig.7) (Table.2)

TABLE (2): Comparison of mean, standard deviation values of postoperative edema of the two groups:

\begin{tabular}{|c|c|c|c|c|c|c|}
\hline & \multicolumn{3}{|c|}{ VAS_GA } & \multicolumn{3}{c|}{ VAS_GB } \\
\cline { 2 - 7 } & 2 days & 5 Days & 7 Days & 2 days & 5 Days & 7 Days \\
\hline Mean & 5.33 & 5.17 & 4.67 & 7.67 & 7.00 & 5.67 \\
\hline SD & 1.67 & 0.39 & 1.15 & 0.98 & 0.85 & 0.78 \\
\hline Min & 2 & 5 & 4 & 6 & 6 & 5 \\
\hline Max & 7 & 6 & 7 & 9 & 0.000 & 7 \\
\hline 5 Days & 0.713 & 0.166 & & 0.000 & & \\
\hline 7 Days & 0.406 & & & & & \\
\hline
\end{tabular}




\section{vii) Postoperative pain:}

The VAS score of the two groups showed statistical significant difference $(\mathrm{P} \leq 0.05)$ between them at all of the follow up intervals $(2,5$ and 7 days post-operatively) in which group A had lower postoperative pain results than that of group B.

(Fig.8)

\section{Objective test:}

\section{Trigeminal Somato-sensory evoked potential (TSEP)}

\section{1-N-Peak latency (ms)}

The mean differences of $\mathrm{N}$ peak latencies preoperative to 2,8 and 24 weeks post-operative at the two groups were $2.71 \pm 1.28,0.98 \pm 0.54$ and $-1.01 \pm 0.49 \mathrm{msec}$ respectively in group $\mathrm{A}$, while in group $\mathrm{B}$ it was $0.19 \pm 0.13,-0.26 \pm 0.12$ and $-0.05 \pm 0.02 \mathrm{msec}$ respectively. Within group A, there was a statistical significant difference in the first interval (pre-operative-2Weeks) ( $\mathrm{p}=0.049)$, no statistical significant change in mean $\mathrm{N}$ through the 2nd interval (Pre-operative -8 Weeks) and 3rd interval (Pre-operative -24 Weeks), as for group B, There was no statistical significant change in mean $\mathrm{N}$ through all follow up periods.

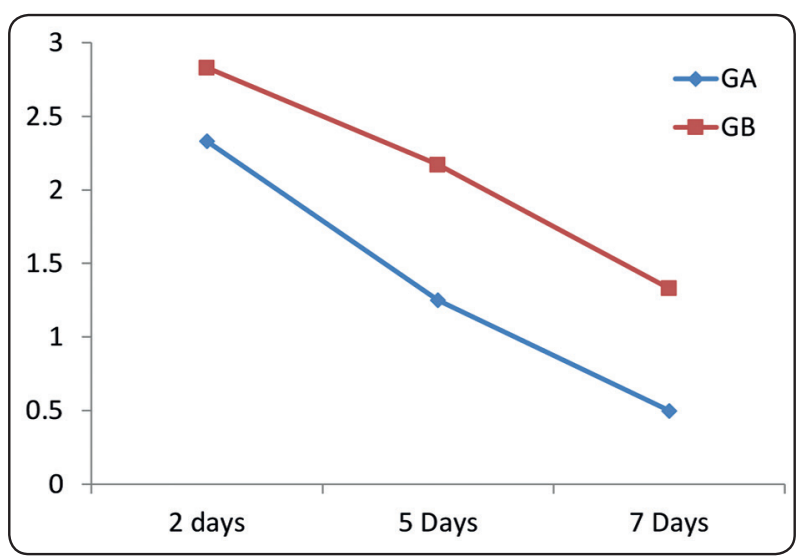

Fig. (7): Line Chart showing postoperative edema at the two groups at 2,5 and 7 days post-operatively.
Comparison of N-peak in both groups revealed a significantly higher mean was recorded in group $\mathrm{B}$ at 2 and 8 weeks, $(p=0.0044, p=0.0082$ respectively). While at 24 weeks, there was no significant difference between both groups.

\section{2-P-Peak latency (ms)}

In group A: The mean difference of $\mathrm{P}$ peak latencies pre-operative to 2,8 and 24 weeks postoperative were $0.5 \pm 0.33,-0.3 \pm 0.38$ and $0.15 \pm 0.12$ msec respectively. While in group $\mathrm{B}$ the mean difference of $\mathrm{P}$ peak latencies pre-operative to 2 , 8 and 24 weeks post-operative were $1.44 \pm 1.17$, $0.22 \pm 0.13$ and $-0.85 \pm 0.41 \mathrm{msec}$ respectively. There was no statistically significant change in mean $\mathrm{P}$ through all follow up periods in both groups.

Comparison of P-peak of both groups revealed a significantly higher mean was recorded in group $\mathrm{B}$ at 2 and 8 weeks, $(\mathrm{p}=0.028, \mathrm{p}=0.05$ respectively). while at 24 weeks, there was no significant difference between the two groups.

\section{3- N-P amplitude $(\mu v)$}

Comparison of N-P amplitude ( $\mu \mathrm{v})$ in both groups revealed a significantly higher mean recorded in group B at 2, 8 weeks and 24 weeks post operative, $(\mathrm{p}=0.0032, \mathrm{p}=0.0027, \mathrm{p}=0.03)$ respectively.

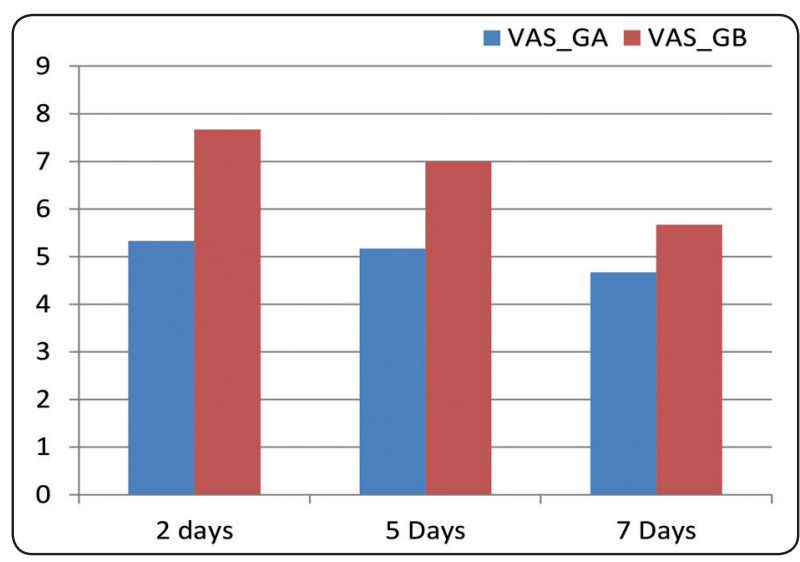

Fig. (8): Bar Chart showing the VAS score of the two groups at 2, 5 and 7 days post-operative. 


\section{DISCUSSION}

Surgeries on posterior mandibular edentulous areas are challenging specially in cases with high degree of mandibular alveolar bone atrophy along with the anatomical restriction caused by the presence of the mandibular canal and its contents, which prevent implants installation at the region ${ }^{[7-10,20]}$.

Our study was designed to assess neurosensory deficits, postoperative pain and edema following inferior alveolar nerve lateralization (IANL) by using Piezosurgery device with simultaneous implant placement versus IANL using the conventional rotary surgical burs with simultaneous implant placement .

Strict and meticulous procedure was followed in the present study since neurological dysfunction of the inferior alveolar nerve bundle and its terminal branches is the major risk. The use of piezoelectric device (for Group A) was based on the conclusions of previous studies ${ }^{[9,10]}$ that considered osteotomy with piezoelectric device is safer and simpler approach for Inferior Alveolar Nerve Lateralization (IANL) surgical technique as it promotes for smaller bone window access without causing injury to the soft tissue, which greatly minimize the risk of injury to the nerve during cutting of the cortical window compared to using conventional rotary instruments. ${ }^{[21]}$

For neurosensory nerve assessment we depended on Patients questionnaires, Light Touch, two points discrimination and Brush Directional Discrimination subjective tests as preliminary evaluations for IAN function in accordance with Antony et al ${ }^{[22]}$ and Juodzbalys et al ${ }^{[20]}$. Due to the weak reliability of previous tests, as they depend mainly on the patient's subjective report of sensory information, Trigeminal Somatosensory Evoked Potential (T.S.E.P) was then used in our study as a quantitative measure for evaluation of IAN function in accordance with Maezawa et al. [24] Rossini et al. ${ }^{[23]}$, Alex R. McDonald et al ${ }^{[25]}$ who suggested the usage of magneto encephalography as an objective monitor for evaluation of posttraumatic inferior alveolar nerve injuries that shows appropriate cortical signal in response to repetitive lip stimulation .

Our subjective neurosensory function tests results revealed that there was statistical significant difference between the two groups at 2 weeks postoperatively; this was in accordance with Hashemi et al, ${ }^{[7]}$ who found $100 \%$ incidence of neurosensory disturbance on the 1 st postoperative week after IANL.

Our study relied upon waveform latency and this is in agreement with other previous literatures ${ }^{[26,27]}$ that suggested waveform latency measurement to be the most reliable, informative, and diagnostic parameter of TSEP. Although the amplitude measurement has been used but could not be defined as a diagnostic parameter to evaluate the IAN function as it showed great variability between patients and even in the same patient each observation period.

The prolongation result in the latencies of first upward $(\mathrm{N})$ and downward $(\mathrm{P})$ peak wave was the most marked features present at our study for sensory impairment postoperatively. Although it is hard to estimate the proportions of damaged fibers in individual nerve injuries, it might be reasonable to expect that latency delays might be a consequence of such injuries. This is consistent with Barkr et al., ${ }^{[28]}$ study who found that latency delay between traumatized and control sides up to 2 or 3 msec could indicate inferior alveolar nerve injuries and Colella et al ${ }^{[29]}$ who showed that preoperative latency period was statistically significant shorter than other postoperative periods in $\mathrm{N}$ and $\mathrm{P}$ peak latencies following bilateral sagittal split osteotomies.

The results of $\mathrm{N}$ and Ppeak latencies demonstrated that the incidence of nerve affection was significantly higher for group B at 2 and 8 week postoperatively, this may indicate that using piezoelectric device for osteotomy for group A was less traumatic than using the conventional rotatory surgical burs for group B. 
At 24 weeks postoperatively our patients in both groups showed full inferior alveolar nerve recovery considered due to indirect nerve damage. Our results are in accordance with previous literature of Pratt et al. ${ }^{[30]}$

In our study, the objective tests results were more sensitive than those of subjective tests. Our result goes in agreement with previous studies [25, 31] which concluded that the differences between subjective and objective assessments may occur. This might be explained that the objective testing (TSEP) in contrast to the conventional clinical test modalities showed an early lower frequency of transient sensory disturbance at early control points while, at late points of follow up the objective assessment corresponded to subjective assessments

Worthy to mention that patients at both groups of our present study subjectively reported more sensory impairment than what could be confirmed objectively by TSEPs testing. This is consistent with results of Bailey et al, ${ }^{[32]}$ who reported that the level of subjective complaint was higher when compared with TSEP following mandibular augmentation procedures. Also our finding comes in agreement with Shintani et al. ${ }^{[33]}$ who revealed that the Subjective assessments are affected by overall physical condition and the state of mind of patients, Nonetheless, subjective assessments combined with objective assessments remain important because subjective assessments might reveal Paraesthesia not indicated in quantitative esthesiometry following lingual nerve repair.

The mean postoperative pain score in the Piezosurgery group (Group A) was statistically significant lesser than the conventional rotary instrument group (Group B). This was in consistent with the finding obtained from Rullo et al ${ }^{[33]}$, Mantovani et al ${ }^{[34]}$ and Barone et al ${ }^{[35]}$ who reported that in cases of simple extraction, there was less pain with piezotome, even though piezotome surgeries required more time compared to conventional rotary instruments. Tsai et al ${ }^{[36]}$ explained the reduction of postoperative pain in piezotome group resulted from the minimal damage of the soft tissues around the bone and due to the decreased heat generation with its use.

Furthermore, our research analyzed the postoperative edema and reveled a statistically significant less postoperative edema in piezo surgeries group (Group A) when compared to the conventional rotary surgeries group (Group B) with better improvement that has been noticed within (Group A) which in accordance with the findings of Pappalardo and Guarnieri ${ }^{[37]}$, Mantovani et al. ${ }^{[34]}$,Piersanti et al. ${ }^{[38]}$ and Mozatti et al. ${ }^{[39]}$ where they compared the postoperative outcomes between piezosurgery and conventional rotary surgery in removing mandibular third molars. Sortino et al ${ }^{[40]}$, Sivolella et al ${ }^{[41]}$ and Mantovani et al ${ }^{[34]}$ who reported that there was a significant decrease in edema with Piezosurgery groups compared to conventional surgery group.

In this study, the duration of the procedure in each group in terms of minutes starting from beginning of the incision until the end of suturing was determined. The mean duration of the operation was longer in the Piezosurgery group than in the conventional rotary instrument group. This was in agreement with Goyal et al. ${ }^{[42]}$ in cases of surgical removal of impacted third molar. Our results showed that while the Piezosurgery required significantly more time when compared to rotary instruments, yet, it resulted in less pain and edema. This was in agreement with the observation by Benediktsdóttir et al ${ }^{[43]}$ who reported that the post-operative results are not relevant to the time required to complete the surgical procedure. It was, however, in consistent with Oikarinen, ${ }^{[44]}$ who reported that pain, swelling and trismus are directly applicable to the duration of the surgical procedure.

It was possible to observe that the procedure assisted by Piezosurgery facilitated the surgical technique, and therefore the operative time was reduced. It also provided more regular osteotomy 
and with less bleeding, thereby improving the visualization of the operative area. Finally, the immediate neural damage was lower on the group treated with the Piezosurgery and with faster recovery. This was in agreement with AulestiaViera ${ }^{[45]}$ when comparing the effect of Piezosurgery versus conventional instrument in inferior alveolar nerve lateralization.

Our results was consistent with the findings of a meta-analysis study conducted by Jiang et al. ${ }^{[46]}$ which included seven studies in their analysis. The aim of their study was to compare Piezosurgery with rotary osteotomy techniques, regarding operation time and the severity of postoperative outcomes, including pain, swelling, and trismus. Their metaanalysis suggested that even though Piezosurgery patients experienced longer operation time; they had less postoperative swelling.

\section{CONCLUSION}

The inferior alveolar nerve lateralization IANL technique using surgical burs has a higher initial rate of sensory dysfunction than the IANL using piezo-surgery. The use peizosurgery had more advantages over conventional rotary instruments, by simplifying the surgical procedure and by reducing bleeding and neural disruption.

Also the somatosensory evoked potential method is considered more informative, reliable and diagnostic parameter than other subjective and conventional clinical methods.

\section{REFERENCES}

1. Vetromilla BM, Moura LB, Sonego CL, Torriani MA, Chagas OL. Complications associated with inferior alveolar nerve repositioning for dental implant placement: a systematic review. Int J Oral Maxillofac Surg 2014;43:13606. http://dx.doi.org/10.1016/j.ijom.2014.07.010.

2. Esposito M, Buti J, Barausse C, Gasparro R, Sammartino G, Felice P. Short implants versuslonger implants in vertically augmented atrophic mandibles: A systematic review of randomised controlled trials with a 5-year postloading follow-up. Int J Oral Implantol 2019;12:267-80.
3. Urban I, Traxler H, Romero-Bustillos M, Farkasdi S, Bartee B, Baksa G, et al. Effectiveness of two different lingual flap advancing techniques for vertical bone augmentation in the posterior mandible: a comparative, split-mouth cadaver study. Int J Periodontics Restorative Dent 2018;38:35-40. http://dx.doi.org/10.11607/prd.3227.

4. Lorean A, Kablan F, Mazor Z, Mijiritsky E, Russe P, Barbu $\mathrm{H}$, et al. Inferior alveolar nerve transposition and reposition for dental implant placement in edentulous or partially edentulous mandibles: a multicenter retrospective study. Int J Oral Maxillofac Surg 2013;42:656-9. http:// dx.doi.org/10.1016/j.ijom.2013.01.020.

5. Alling CC. Lateral repositioning of the inferior alveolar neurovascular bundle. J Oral Surg 1977;35:419.

6. Jensen O, Nock D. Inferior alveolar nerve repositioning in conjunction with placement of osseointegrated implants: a case report. Oral Surg Oral Med Oral Pathol 1987;63:2638. http://dx.doi.org/10.1016/0030-4220(87)90187-3.

7. Hashemi HM. Neurosensory function following mandibular nerve lateralization for placement of implants. Int. J Oral Maxillofac Surg. 2010; 39: 452-456. https://doi. org/10.1016/j.ijom.2010.02.003

8. Rathod M, Kshirsagar RA, Joshi S, et al. Evaluation of Neurosensory Function Following Inferior Alveolar Nerve Lateralization for Implant Placement. J Maxillofac Oral Surg. 2019; 18:273-279. https://doi.org/10.1007/s12663018-1124-1

9. Scarano A, Sinjari B, Murmura G, Lorusso F. Neurosensory Disturbance of the Inferior Alveolar Nerve After 3025 Implant Placements. Implant Dent. 2017; 26:735-743 https://doi.org/10.1097/ID.0000000000000651

10. Palacio García-Ochoa A, Pérez-González F, Negrillo Moreno A, et al. Complications associated with inferior alveolar nerve reposition technique for simultaneous implant-based rehabilitation of atrophic mandibles. A systematic literature review [published online ahead of print, 2020 Jan 2]. J Stomatol Oral Maxillofac Surg. 2020; 30296-4. https://doi.org/10.1016/j.jormas.2019.12.010

11. Rodriguez JG, Eldibany RM. Vertical splitting of the mandibular body as an alternative to inferior alveolar nerve lateralization. Int J Oral Maxillofac Surg 2013;42:1060-6. http://dx.doi.org/10.1016/j.ijom.2013.04.014.

12. Khajehahmadi S, Rahpeyma A, Bidar M, Jafarzadeh H. Vitality of intact teeth anterior to the mental foramen after inferior alveolar nerve repositioning: nerve 
transpositioning versus nerve lateralization. Int $\mathrm{J}$ Oral Maxillofacial Surg 2013;42:1073-8. http://dx.doi. org/10.1016/j.ijom.2013.04.012.

13. Gasparini G, Boniello R, Saponaro G, Marianetti TM, Foresta E, Torroni A, et al. Long term follow-up in inferior alveolar nerve transposition: our experience. BioMed Res Int 2014;2014:170602. http://dx.doi. org/10.1155/2014/170602.

14. Khojasteh A, Hassani A, Motamedian SR, Saadat S, Alikhasi M. Cortical bone augmentation versus nerve lateralization for treatment of atrophic posterior mandible: a retrospective study and review of literature. Clin Implant Dent Relat Res 2016;18:342-59. http://dx.doi.org/10.1111/ cid.12317.

15. Vasco MAA, Hecke MB, Bezzon OL. Analysis of short implants and lateralization of the inferior alveolar nerve with 2-stage dental implants by finite element method. J Craniofac Surg 2011;22:2064-71. http://dx.doi.org/ 10.1097/SCS.0b013e318231993d.

16. Eggers G,Klein J,Blank J and Hassfeld S. Piezosurgery: an ultrasound device for cutting bone and its use and limitations in maxillofacial surgery. J Oral Maxillofac Surg 2004; 42 (5): 451-3.

17. Shaheen H, Behery G, Helmy E. Inferior alveolar nerve lifting: Conventional versus piezosurgery. 2011; MSc. Oral and Maxillofac Surg department, Faculty of oral and dental medicine

18. Naves Freire AE, Iunes Carrera TM, Rodriguez LS, et al. Piezoelectric Surgery in the Inferior Alveolar Nerve Lateralization with Simultaneous Implant Placement: A Case Report. Implant Dent. 2019; 28:86-90. https://doi. org/10.1097/ID.0000000000000855

19. de Vicente JC, Peña I, Braña P, Hernández-Vallejo G. The use of piezoelectric surgery to lateralize the inferior alveolar nerve with simultaneous implant placement and immediate buccal cortical bone repositioning: a prospective clinical study. Int J Oral Maxillofac Surg. 2016; 45:851857. https://doi.org/10.1016/j.ijom.2016.01.017

20. Juodzbalys G, Wang HL, Sabalys G. Injury of the Inferior Alveolar Nerve during Implant Placement: a Literature Review. J Oral Maxillofac Res. 2011; 2(1):e1. https://doi. org/10.5037/jomr.2011.

21. Chan HL, Benavides E, Yeh CY, Fu JH, Rudek IE, Wang HL. Risk assessment of lingual plate perforation in posterior mandibular region: a virtual implant placement study using cone-beam computed tomography. J Periodontol. 2011; 82(1):129-135. https://doi.org/10.1902/ jop.2010.100313

22. Antony PG, Sebastian A, Varghese KG, et al. Neurosensory evaluation of inferior alveolar nerve after bilateral sagittal split ramus osteotomy of mandible. J Oral Biol Craniofac Res. 2017;7(2):81-88. https://doi.org/10.1016/j. jobcr.2017.03.004

23. Rossini C, Luigetti M, Romanello R, et al. Somatosensory Evoked Potentials of Inferior Alveolar Nerve: confirmation of a possible non-invasive

24. Maezawa H, Matsuhashi M, Yoshida K, Mima $T$, Nagamine T, Fukuyama H. Evaluation of lip sensory disturbance using somatosensory evoked magnetic fields. Clin Neurophysiol. 2014; 125:363-369. https://doi. org/10.1016/j.clinph.2013.07.017

25. McDonald AR, Roberts TP, Rowley HA, Pogrel MA. Noninvasive somatosensory monitoring of the injured inferior alveolar nerve using magnetic source imaging. J Oral Maxillofac Surg. 1996; 54(9):1068-1074. https://doi. org/10.1016/s0278-2391(96)90161-5

26. Drechsler F, Neuhauser B. Somatosensory trigeminal evoked potentials in normal subjects and in patients with trigeminal neuralgia before and after thermocoagulation of the ganglion Gasseri. Electromyogr Clin Neurophysiol. 1986; 26:315-326.

27. Stöhr M, Petruch F. Somatosensory evoked potentials following stimulation of the trigeminal nerve in man. J Neurol. 1979; 220:95-98. https://doi.org/10.1007/ BF00313949

28. Barker GR, Bennett AJ, Wastell DG. Applications of trigeminal somatosensory evoked potentials (TSEPs) in oral and maxillofacial surgery. Br J Oral Maxillofac Surg. 1987;25:308-313 https://doi.org/10.1016/02664356(87)90070-2

29. Colella G, Cannavale R, Vicidomini A, Lanza A. Neurosensory disturbance of the inferior alveolar nerve after bilateral sagittal split osteotomy: a systematic review . Journal of Oral and Maxillofacial Surgery 2007; 65:17071715. https://doi.org/10.1016/j.joms.2007.05.009

30. Pratt H, Starr A. Mechanically and electrically evoked somatosensory potentials in human: scalp and neck distributions of short latency components. Electroencephalogr Clin Neurophysiol. 1981; 51:138-147. https://doi.org/10.1016/0013-4694(81)90002-X 
31. Hashiba Y, Ueki K, Marukawa K, et al. A comparison of lower lip hypoesthesia measured by trigeminal somatosensory-evoked potential between different types of mandibular osteotomies and fixation. Oral Surg Oral Med Oral Pathol Oral Radiol Endod. 2007; 104:177-185. https://doi.org/10.1016/j.tripleo.2006.11.038

32. Bailey PH, Bay RA. Evaluation of long term sensory changes following mandibular augmentation procedures. J Oral Maxillofac Surg. 1984; 42:722. https://doi. org/10.1016/0278-2391(84)90420-8

33. Shintani Y, Nakanishi T, Ueda M, Mizobata N, Tojyo I, Fujita S. Comparison of Subjective and Objective Assessments of Neurosensory Function after Lingual Nerve Repair. Med Princ Pract. 2019;28(3):231-235 https://doi.org/10.1159/000497610

34. Rullo R, Addabbo F, Papaccio G, D'Aquino R, Festa VM: Piezoelectric device vs. Conventional rotative instruments in impacted third molar surgery: Relationships between surgical difficulty and postoperative pain with histological evaluations. J Craniomaxillofac Surg; 41:e33-8, 2013.

35. Mantovani E, Arduino PG, Schierano G, Ferrero L, Gallesio G, Mozzati M, : A split-mouth randomized clinical trial to evaluate the performance of piezosurgery compared with traditional technique in lower wisdom tooth removal. J Oral Maxillofac Surg; 72:1890-7, 2014.

36. Barone A, Marconcini S, Giacomelli L, Rispoli L, Calvo JL, Covani U: A randomized clinical evaluation of ultrasound bone surgery versus traditional rotary instruments in lower third molar extraction. J Oral Maxillofac Surg; 68:330-6, 2010 .

37. Tsai S-J, Chen Y-L, Chang H-H, Shyu Y-C, Lin C-P. : Effect of piezoelectric instruments on healing propensity of alveolar sockets following mandibular third molar extraction. Journal of Dental Sciences; 7: 296-300, 2012.

38. S. Pappalardo and R. Guarnieri : "Randomized clinical study comparing piezosurgery and conventional rotatory surgery in mandibular cyst enucleation," Journal of CranioMaxillofacial Surgery, vol. 42, no. 5, pp. e80-e85, 2014.
39. L. Piersanti, M. Dilorenzo, G. Monaco, and C. Marchetti: "Piezosurgery or conventional rotatory instruments for inferior third molar extractions?" Journal of Oral and Maxillofacial Surgery, vol. 72, no. 9, pp. 1647-1652, 2014.

40. M. Mozzati, G. Gallesio, A. Russo, G. Staiti, and C. Mortellaro:"Third-molar extraction with ultrasound bone surgery: A CaseControl Study," Journal of Craniofacial Surgery, vol. 25, no. 3, pp. 856-859, 2014.

41. Sortino F, Pedullà E, Masoli V. : The piezoelectric and rotatory osteotomy technique in impacted third molar surgery: Comparison of postoperative recovery. J Oral Maxillofac Surg; 66:2444-8, 2008.

42. Sivolella S, Berengo M, Bressan E, Di Fiore A, Stellini E.: Osteotomy for lower third molar germectomy: Randomized prospective crossover clinical study comparing Piezosurgery and conventional rotatory osteotomy. J Oral Maxillofac Surg; 69:e15-23, 2011.

43. M. Goyal, K. Marya, A. Jhamb et al.: "Comparative evaluation of surgical outcome after removal of impacted mandibular third molars using a Piezotome or a conventional hand piece: A Prospective Study," British Journal of Oral and Maxillofacial Surgery, vol. 50, no. 6, pp. 556-561, 2012

44. Benediktsdóttir IS, Wenzel A, Petersen JK, Hintze H.: Mandibular third molar removal: Risk indicators for extended operation time, postoperative pain, and complications. Oral Surg Oral Med Oral Pathol Oral Radiol Endod; 97:438-46, 2004.

45. Oikarinen K.: Postoperative pain after mandibular third-molar surgery. Acta Odontol Scand; 49:7-13, 1991

46. Aulestia-Viera PV, Sousa SS, Barboni MMJ, et al.: Comparison between the piezosurgery and the conventional rotary surgery in the lateralization of the inferior alveolar nerve. Rev Cubana Estomatol. 2017;54(4):1-9.

47. Q. Jiang, Y. Qiu, C. Yang, J. Yang, M. Chen, and Z. Zhang: "Piezoelectric versus conventional rotary techniques for impacted third molar extraction: a meta-analysis of randomized controlled trials," Medicine, vol. 94, no. 41, Article ID e1685, 2015. 